\title{
Preparation and stability of silica sol/TPGDA dispersions and its application in the UV-curable hybrid coatings for fire protection
}

\author{
Dan Shang • Xiaoying Sun · Jianzhong Hang • \\ Lujiang Jin $\cdot$ Liyi Shi
}

Received: 13 December 2012/ Accepted: 18 April 2013/Published online: 30 April 2013

(C) The Author(s) 2013. This article is published with open access at Springerlink.com

\begin{abstract}
A series of silica sols modified by $\gamma$-methacryloxypropyltrimethoxysilane (MPS) were synthesized by the acid-catalyzed sol-gel method, and then the solvent in these sols were extracted under several vacuum distillation conditions. The stability of the sol after the distillation can be improved by means of increasing the dosage of MPS and incorporating reactive diluent TPGDA into the sol as new dispersion medium. Optimized samples have maintained stable for over 180 days. The sol dispersions and UV-curable organic compounds were mixed to form the hybrid coatings for fire protection. Effects of the distillation treatment and the cosolvent anhydrous ethanol added into the reaction solution on thermal and combustion performances and physical properties of the hybrid coatings were studied by thermogravimetric analysis, microscale combustion calorimeter, limit oxygen index test and UL-94 horizontal test, etc. The results showed that the distillation treatment for the sol was necessary to improve thermal performance and physical properties of the hybrid coatings. In addition, in the flammability experiment, hybrid coatings showed a quick and efficient protection of the substrate.
\end{abstract}

D. Shang · L. Shi

School of Material Science and Engineering, Shanghai University, Shanghai 200072, People's Republic of China e-mail: dshang33@126.com

X. Sun $(\bowtie) \cdot$ J. Hang $\cdot$ L. Jin $\cdot$ L. Shi $(\bowtie)$

Nano-Science and Technology Center, Shanghai University, Shanghai 200444, People's Republic of China

e-mail: xysun@shu.edu.cn

L. Shi

e-mail: shiliyi@shu.edu.cn
Keywords Sol-gel · Organic-inorganic hybrid coating materials · UV-curable - Sol dispersion - Epoxy acrylate . Fire protection

\section{Introduction}

In recent years, organic-inorganic hybrid materials have been extensively investigated as a promising advanced materials because they combine advantages of inorganic and organic materials $[1,2]$. Usually, most organic-inorganic hybrid materials are thermally cured [3-5], but some of them are cured by UV light yet [6-12]. This class of materials are very promising in the UV cured coating field because it combines the advantages of traditional hybrid materials and UV-curing technique, mainly including highspeed process, lower energy consumption as well as the curing process occurs at ambient temperature, lower process costs, high chemical stability of materials and lower VOCs (volatile organic compounds) of UV-curing technique [13, 14], and the improvement of thermal and mechanical properties etc., due to micro-scale homogeneous network of the organic-inorganic hybrid material $[1,15]$.

Inorganic phase of UV-curable organic-inorganic hybrid materials is mainly prepared by sol-gel method which contains large amounts of the solvent. However, the rapid curing process of UV technology can cause that the solvent introduced by the sol is difficult to be removed. As a consensus, the residual solvent could weaken some performance of the UV-cured hybrid material. Therefore, to decrease or remove the solvent in sol solution becomes the essential work. The cosolvent-free sol-gel method [16-18] can reduce the solvent content in the sol. However, the common practice was that the sol solution alone or mixed with UV-curable organic components, and then is distilled by the vacuum distillation 
[19-21]. The storage time of the sol after the distillation has been recognized as the significant factor in practical use for UV-curable coating application. However, the stability of the sol after the distillation, and the effect of the residual solvent on the properties of the UV-cured hybrid coating materials was not specifically quantified.

It is clear that the concentrated sol is very unstable because the mutual collision chance of colloidal particles in the concentrated sol sharply increases. Some attempt may be considered to maintain its stability. For instance, selecting the appropriate structure of the silane coupling agents and adjusting its dosage, or adding the substitution of solvents in the sol. In the study on preparation of UV-curable hybrid materials, $\gamma$-methacryloxypropyltrimethoxysilane (MPS) is the most commonly used coupling agent due to its $\mathrm{C}=\mathrm{C}$ group allows the inorganic phase to form a chemical bond with the organic phase [22-27]. It is also available to improve the stability of the concentrated sol because its long molecule chain is expected to hinder the collision of the colloidal particles. In addition, reactive diluent is the ideal substitute of solvents in the sol because it is the basic ingredient of the UV-curing formation with a low viscosity, and can be completely cured in the UV curing reaction [28].

Accordingly, in this study, we prepared a series of silica sols by the acid-catalyzed sol-gel method, and then the blend of the sols and/or having no tripropylene glycol diacrylate (TPGDA) was distilled under several vacuum distillation conditions to form the silica sol/TPGDA dispersions. The method to improve the stability of the sol and the sol/TPGDA dispersions after the vacuum distillation was discussed in detail. Moreover, the silica sol/TPGDA dispersions and the UV-curable organic compound mixed to form the UV-cured hybrid coating materials for fire protection, and then their thermal stability, the combustion performance and physical properties were investigated.

\section{Experimental section}

\subsection{Materials}

The epoxy acrylate of bisphenol A (brand name: SM6104) was obtained by Jiangsu Sanmu (Group) Co. Jiangsu, China. Anhydrous ethanol and glacial acetic acid (HAc) were purchased from SinoPharm Chemical Reagent Co., Ltd. Shanghai, China. Tetraethoxysilane (TEOS), $\gamma$-methacryloxypropyltrimethoxysilane (MPS) were obtained from Shanghai Silicon Mountain Macromolecular Materials Co., Ltd. Shanghai, China. Tripropylene glycol diacrylate (TPGDA) was got from Wuxi tianjiaosaite material., Ltd. Jiangsu, China. Darocure 1173 photoinitiator was purchased from Zhengjiang Fanyyang Chemical Co., Ltd. Zhengjiang, China. Deionized water was offered by our laboratory.

\subsection{Preparation and treatment of silica sols}

Inorganic part of the hybrid system is composed of MPS and TEOS. The different mol ratio TEOS, MPS and/or no anhydrous ethanol were fed into a three-neck flask equipped with a mechanical stirrer, dropping funnels, and then deionized water and HAc were dropwise added into the mixture with a high stirring rate at room temperature. The reaction mentioned above was carried out under constantly stirring rate for $8 \mathrm{~h}$ to obtain transparent sol, and then aged for $12 \mathrm{~h}$. The blend of silica sol and TPGDA was condensed under vacuum at the certain temperature to extract the residual ethanol and water, and then silica sol dispersion with TPGDA as dispersing media was obtained. Mass ( $g$ ) of residual solvent divided by mass $(\mathrm{g})$ of the sol was defined as a content (wt\%) of residual solvent after the distillation. In all formulations were prepared, detail of formulation was listed in Table 1. Deterioration time (time to partial or complete loss of fluidity) of these silica sol dispersions was recorded.

\subsection{Preparation of UV-curable organic-inorganic hybrid coating materials}

Silica sols or the distilled silica sol/TPGDA dispersions, UV-curable organic composition (SM6104 and TPGDA), and photoinitiator 1173 (4 wt\% of sol and organic composition) were stirred at room temperature to form a homogeneous solution. The weight ratio of the sol, SM6104 and TPGDA (including the part in the distilled sol dispersion) equals to $4 / 3.6 / 2.4$. The coating solution was directly cast on glass, and then was cured by UV light (High pressure mercury lamp with a wavelength of $365 \mathrm{~nm}$ ) with the power of 1,000 W (Shanghai Guoda UV Equipment Co., Ltd). Cured hybrid coating materials detached from the glass substrate were characterized. Another part of the coating solution is coated the glass and wood floor using an $80 \mu \mathrm{m}$ wire-gauged bar applicator mainly for testing physical properties of cured film.

Table 1 Composition of raw materials joined sol-gel reaction (unit: $\mathrm{mol})$

\begin{tabular}{llllll}
\hline Sample & TEOS & MPS & Ethanol & Water & HAc \\
\hline T1K0.5E0 & 1 & 0.5 & 0 & 3 & 0.09 \\
T1K0.5E3 & 1 & 0.5 & 3 & 3 & 0.15 \\
T1K1E0 & 1 & 1 & 0 & 4 & 0.12 \\
T1K1E4 & 1 & 1 & 4 & 4 & 0.2 \\
T1K2E0 & 1 & 2 & 0 & 6 & 0.18 \\
T1K2E6 & 1 & 2 & 6 & 6 & 0.3 \\
T1K3E0 & 1 & 3 & 0 & 8 & 0.24 \\
T1K3E8 & 1 & 3 & 8 & 8 & 0.4 \\
\hline
\end{tabular}


Moreover, the blank, namely, the pure organic coating as the additional sample was composed of SM6104 and TPGDA with the weight ratio of $6 / 4$ to form the UV-cured film using the same operation.

\subsection{Characterization}

FTIR spectra of the materials was recorded between 4,000 and $400 / \mathrm{cm}$ on a Nicolet Avatar 370 FTIR spectrometer, USA. Samples were ground into fine powders and doped with $\mathrm{KBr}$. A minimum of 32 scans was signal-averaged with a resolution of $2 / \mathrm{cm}$ at the $4,000-400 / \mathrm{cm}$ range.

The morphology and diameter of the sols were evidenced by transmission electron microscopy (TEM) on a JEOL JEM-200Cx microscopy. The dispersions were diluted with ethanol and ultrasonicated for $30 \mathrm{~min}$ and then dried onto carbon-coated copper grids before examination.

Scanning electron microscopy of the gold-coated hybrid coating materials was examined by a JEOL Model JSM6700F SEM system.

Thermogravimetric analysis (TGA) was performed using a USA TA Instruments Model Q500 instrument from the room temperature to $700{ }^{\circ} \mathrm{C}$ in nitrogen with a heating rate of $20^{\circ} \mathrm{C} / \mathrm{min}$.

MCC tests were carried out on a Govmak MCC-2 microscale combustion calorimeter, which was used to investigate the combustion of the UV-cured hybrid coating materials. The limit oxygen index (LOI) test was carried according to the GBT 2406-93 standard for the test specimen bars of $120 \mathrm{~mm}$ in length, $60 \mathrm{~mm}$ in width, and $3 \mathrm{~mm}$ in thickness. The UL-94 horizontal test was performed according to the UL-94 standard with the test specimen bars of $125 \mathrm{~mm}$ in length, $13 \mathrm{~mm}$ in width, and $3 \mathrm{~mm}$ in thickness. Required time to burn the specimen with $75 \mathrm{~mm}$ in length was recorded, and then converted to their flame propagation velocity $(\mathrm{mm} / \mathrm{min})$. In addition, the flammability experiment of coatings was performed in the flammability test chamber, and the height of experimental fire is $4 \mathrm{~mm}$, and its duration time is $60 \mathrm{~s}$. Morphology of coatings after combustion was recorded by optical digital camera.

The abrasion resistance was carried out by subjecting the coated wood floor substrate to a standardized Taber abrasion test (GB/T 15036.2-2001). CS-0 rubber wheels covered by NO.180 sandpaper strips were used and $500 \mathrm{~g}$ load on each wheel. The substrates were allowed to be abraded cumulatively to 100 cycles. The scratch resistance test of coatings was performed on the automatic scratch tester (REF.705, SHEEN INSTRUMENTS). The coated glass plate is fixed in skateboarding and moved slowly with the skateboard. Meanwhile, the needle with a certain load glided over the surface. The minimum load to pierce the film was recorded. Pendulum hardness (ASTM D4366) and pencil hardness(ASTM D3363) were also performed in accordance with the corresponding standard test methods as indicated. Cross-cut measurement (ASTM D3359) was also performed in accordance with the corresponding standard test methods as indicated using a QFH Cross Hatch Cutter (Shanghai XianDai Environment Engineering Technique Co., Ltd, China). The transparency was examined with a Nippon Denshoku 300A instrument in accordance with the ASTM D1003 standard.

\section{Results and discussion}

\subsection{Synthesis and morphology of the sol}

FTIR spectra of the sol T1K2E6 and its precursors, and two complementary samples (unreacted TEOS and MPS) are shown in Fig. 1, respectively. From the comparison between the spectrum 3 and the spectrum 4 , it is found that several differences occur at four regions $(3,423-3,437$, $2,842,1,087$ and $812-790 / \mathrm{cm})$. The broad absorption band at $3,423-3,437 / \mathrm{cm}$ is attributed to stretching vibrations involving -OH groups [18]. Its position moved from 3,423 to $3,437 / \mathrm{cm}$, and its intensity obviously increased after hydrolysis. Several absorption peaks occurring in the range of 2,842 to $2,978 / \mathrm{cm}$ are assigned to the $\mathrm{C}-\mathrm{H}$ stretching vibration [29]. From the comparison of the spectra (1-3), it can be found that the absorption peak at $2,842 / \mathrm{cm}$ is the $\mathrm{C}-\mathrm{H}$ bond relates to $-\mathrm{OR}$ groups of MPS. It disappeared after hydrolysis. The vibrations peak at $1,087 / \mathrm{cm}$ is assigned to $\left(\mathrm{v}_{\mathrm{a}}(\mathrm{Si}-\mathrm{OCO})\right)$ [30] in the spectrum 3 , and replaced by new broaden peak at $1,094 / \mathrm{cm}$ after hydrolysis. The change implies the formation of the $\mathrm{Si}-\mathrm{O}-\mathrm{Si}$ networks involving the hydrolysis products of TEOS and MPS with the mutual linkage [31]. The absorption peaks of $812 / \mathrm{cm}$ and $790 / \mathrm{cm}$ which are assigned to methoxy groups rocking

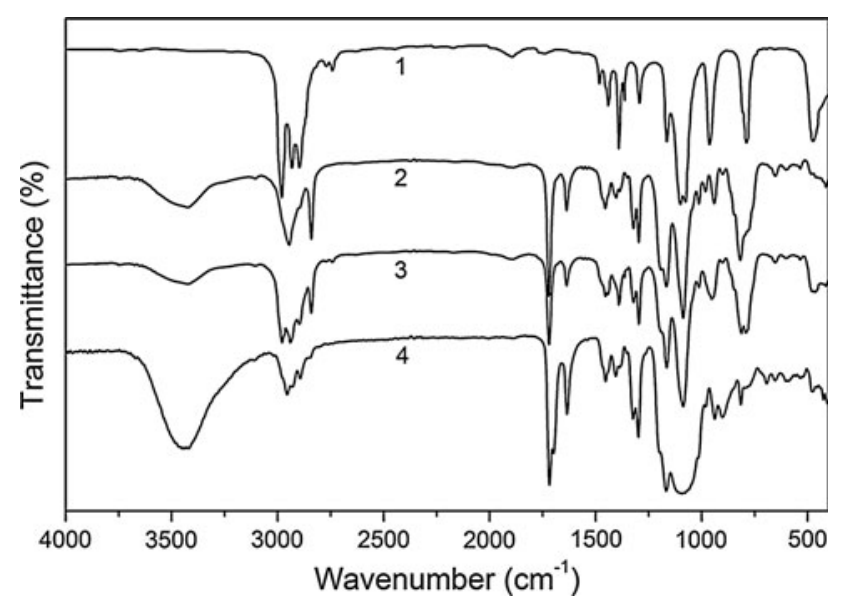

Fig. 1 The FTIR spectra of 1 unreacted TEOS and 2 MPS, 3 the precursors of T1K2E6, and 4 the sol T1K2E6 
vibration [32] of MPS and $\mathrm{Si}-\mathrm{O}_{4}$ asymmetric stretching vibration [24, 33] almost faded after hydrolysis. These results suggest the hydrolysis of the alkoxy groups of TEOS and MPS and the formation of MPS-modified silica sol.

The morphology of sols involved in ethanol and ethanolfree was investigated by TEM, and shown in Fig. 2a, b. Size distributions acquired from their TEM images were shown in Fig. 2c. As can be seen from Fig. 2a, b, sol T1K2E6 is composed of aspheric colloid particles. In fact, these colloid particles are the aggregates of smaller shapefree units with diameters of $10-20 \mathrm{~nm}$, while the sol T1K2E0 is composed of independent spherical units with diameters of tens of nanometers to a few microns. From Fig. 2c, it can be clear that colloid particles size distribution of the sol T1K2E6 is from about 30-300 nm, mainly at about $100 \mathrm{~nm}$, while colloidal particles of the sol T1K2E0 have diameters in the border range of about $30-1,500 \mathrm{~nm}$, mainly at about $150 \mathrm{~nm}$. This result suggested that anhydrous ethanol as the cosolvent has a very large impact on the morphology of the produced sol. By means of the Fig. 3, morphological differences of colloid particles in the two sol are explained. On the one hand, in the hydrolysis reaction involved in ethanol, the mutual solubility of water phase and organic phase has been a very big improvement, and two phases can be mixed in the nanoscale or smaller scale with each other, so that the hydrolysis reaction is rapid and uniform [34, 35]. Primary colloidal particles with small size and high surface activity were prepared after undergoing hydrolysis and condensation. They would form aggregates because of their highly activity [36]. However, condensation reaction is hindered in the region of existing the large number of organic groups of MPS, and is carried on smoothly only in the region of having a lot of $\mathrm{Si}-\mathrm{OH}$ groups. On the other hand, in the hydrolysis reaction without ethanol, it was observed by naked eyes that the stirring solution was opaque for a few hours. As we all know, immiscible two phases can form the emulsion by means of stirring. This phenomenon implies that two phases form the emulsion which their size distribution should be very wide because of having no emulsifiers [37]. Furthermore, in this reaction system, hydrolysis is uneven and inefficient only by means of the interface collision provided by mechanical stirring. Thereby, collide particles with wide size distribution and low surface activity are produced. They are stable and do not aggregate largely in the subsequent aging process [36].

\subsection{Stability of the sol dispersion}

The effect of different distillation time on deterioration time of the sol dispersion T1K0.5E3/TPGDA was quantified firstly, and distillation temperature was $50{ }^{\circ} \mathrm{C}$, and the result was shown in Fig. 4a. Distillation time was $40 \mathrm{~min}$, deterioration time of T1K0.5E3/TPGDA was 60 days, but distillation time increased to $120 \mathrm{~min}$, its deterioration time

Fig. 2 TEM images of the sols a T1K2E6, b T1K2E0 and their size distributions

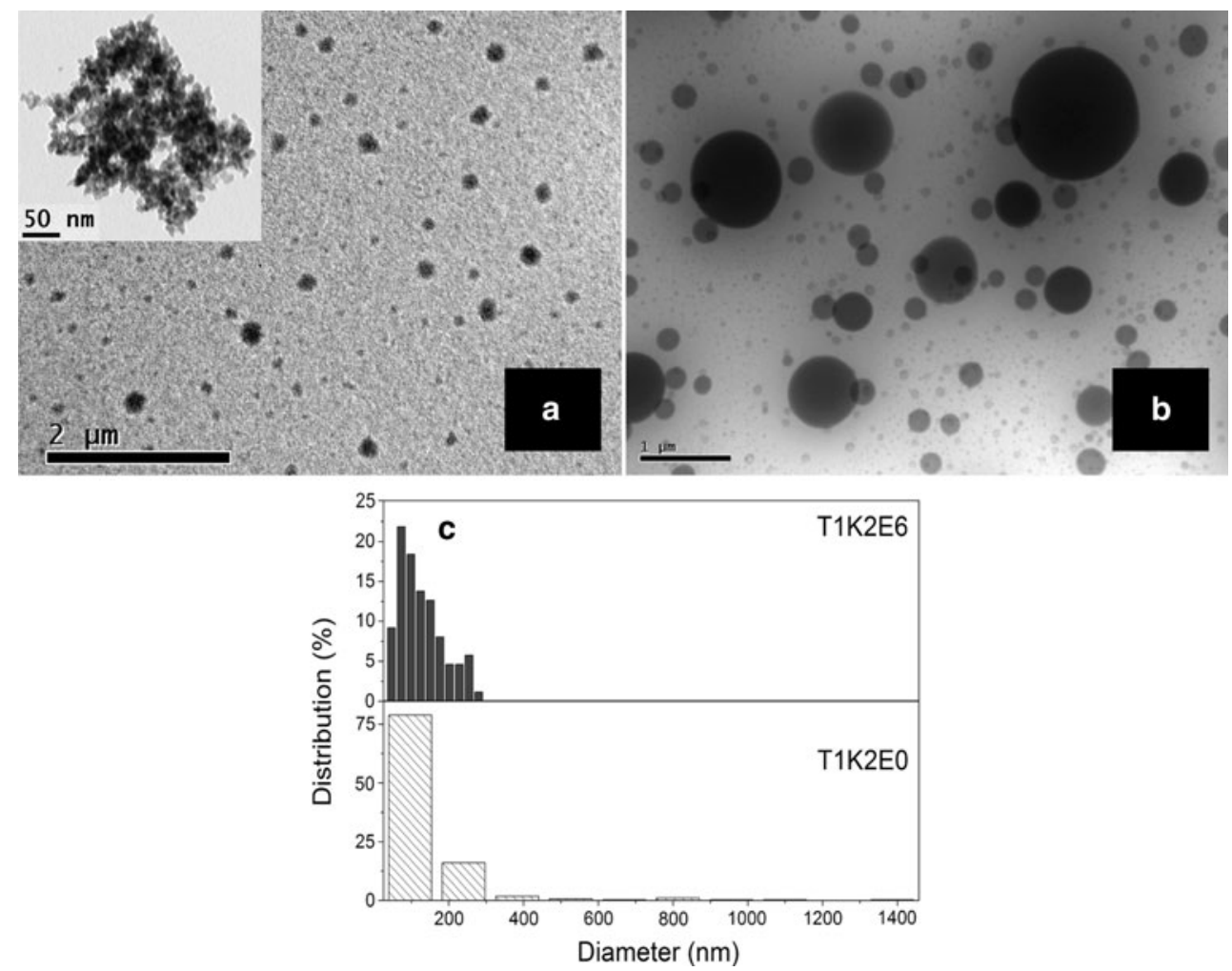




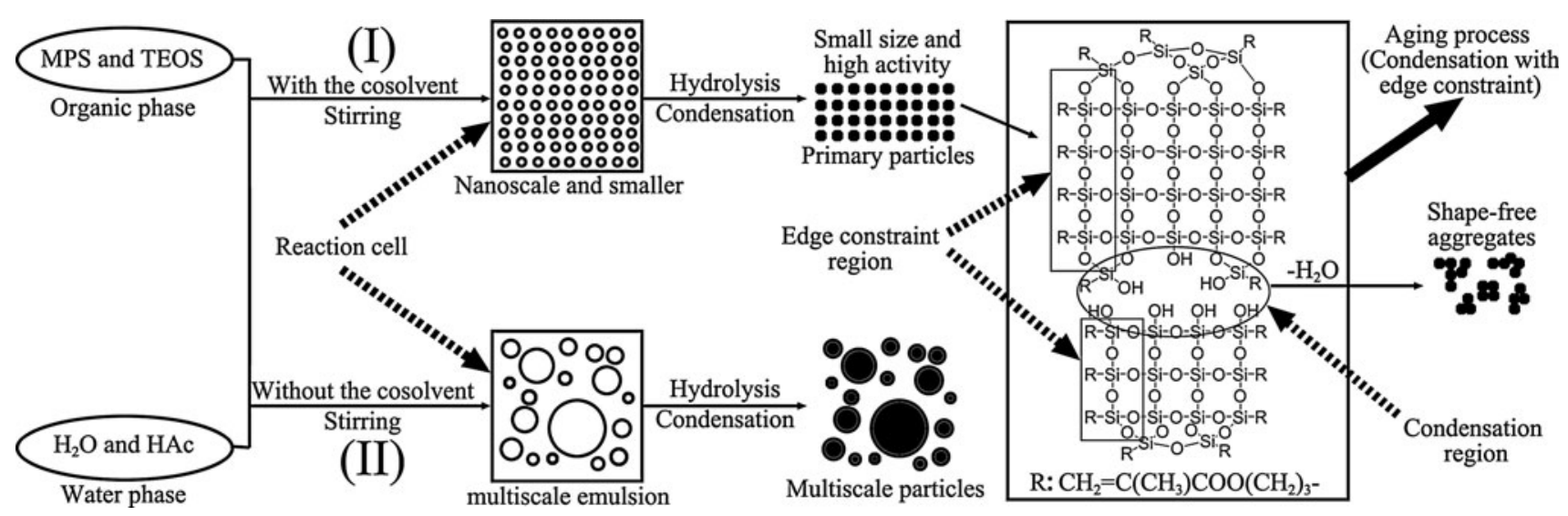

Fig. 3 Schematic representation of the collide particle growth of T1K2E6 (process I) and T1K2E0 (process II)

reduced to about 15 days, and when distillation time increased to $240 \mathrm{~min}$ again, T1K0.5E3/TPGDA completely solidified in about 2 days. Moreover, the effect of different distillation temperatures on its deterioration time was also quantified, and distillation time was $40 \mathrm{~min}$, and the result was shown in Fig. 4b. When distillation temperature was $50{ }^{\circ} \mathrm{C}$, its deterioration time was 60 days, and when distillation temperature was $80^{\circ} \mathrm{C}$, it completely solidified in about 1 day. However, these two figures also showed that in two distillation conditions, content of the solvent (except for TPGDA) and deterioration time have the same changing trend. It is obvious that distillation time and temperature are not the root cause, but changing the solvent content in sol, resulting in shorter deterioration time of the sol. The effects of distillation conditions of other samples on their deterioration times are similar to T1K0.5E3/TPGDA, and not be repeated here.

As an alternative solvent, whether TPGDA was helpful to the stability of the sol after the distillation was also investigated, and the result was shown in Fig. 5. In this experiment, each sol was divided into two, one is the sol with TPGDA as alternative solvent (see Sect. 2.2: its added amount), and another is the sol without TPGDA. Content of residual solvents in each group of samples for comparison is the same (the difference less than $1 \mathrm{wt} \%$ ). From Fig. 5, it can be seen that deterioration time of every sample with TPGDA is much longer than another. Among them, deterioration time of T1K0.5E3/TPGDA is about 30 days, longer 22 days than T1K0.5E3 after the distillation, and deterioration time of T1K1E4/TPGDA is about 40 days, longer 25 days than T1K1E4 after the distillation. When the mole ratio of sol precursors MPS and TEOS was equal to $2 / 1$ and $3 / 1$, the gap of deterioration time increased to about 120 and 90 days, respectively. The results unambiguously showed that TPGDA as an alternative solvent to add into the sol solution, can greatly improve the stability of the sol after the distillation, particularly in samples having a more sol precursor MPS.

Figure 6 showed deterioration time of different sol dispersions with the same content (the difference less than
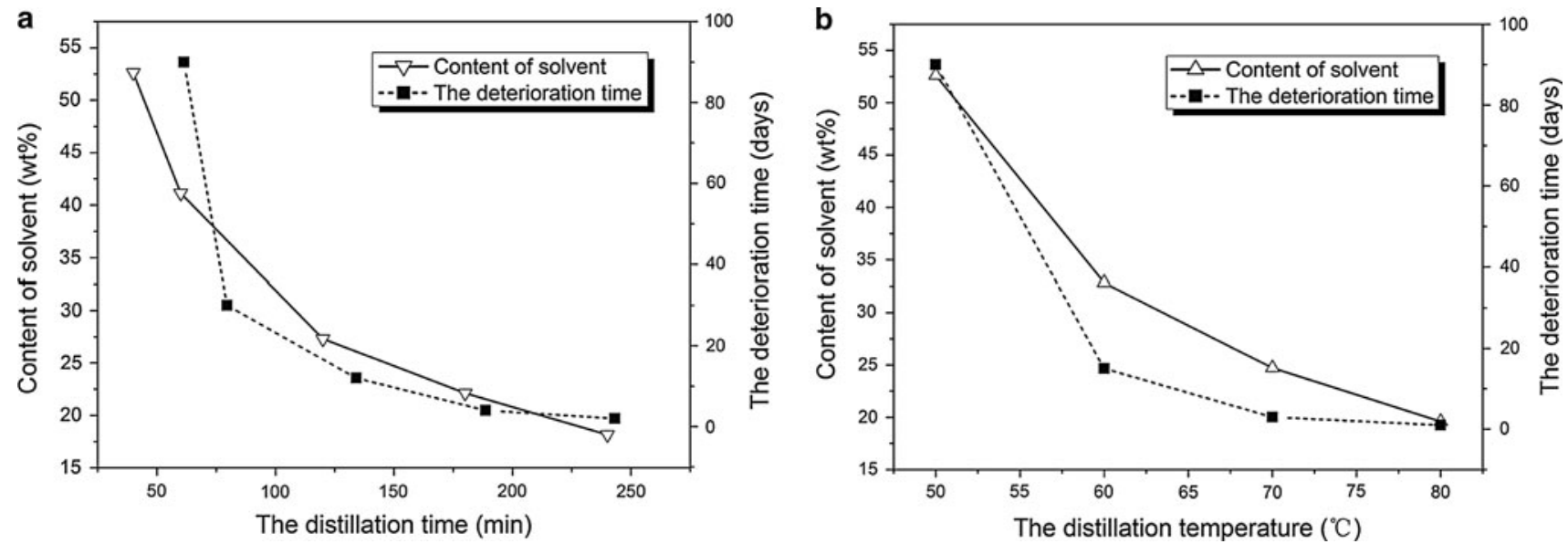

Fig. 4 The effects of the distillation time (a) and temperature (b) on the deterioration time of T1K0.5E3/TPGDA dispersions 


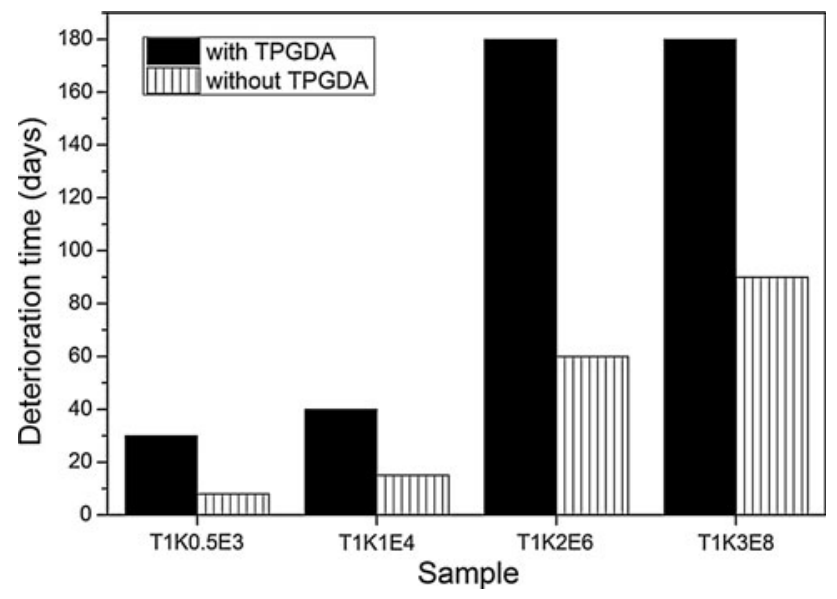

Fig. 5 The effects of TPGDA on deterioration time of the sol

$1 \mathrm{wt} \%$ ) of residual solvents. As can be seen from this figure, on the one hand, deterioration times of several sol dispersions T1K0.5E0/TPGDA, T1K0.5E3/TPGDA, T1K1E0/TPGDA and T1K1E4/TPGDA are much shorter than the other samples. The sol precursor MPS is only variable. When the molar ratio between MPS and TEOS increased from $1 / 1$ to $2 / 1$, deterioration time increased from about 20 days of T1K1E0/ TPGDA and T1K1E4/TPGDA to $>180$ days of T1K2E0/ TPGDA and T1K2E6/TPGDA. This means that to increase the content of the sol precursor MPS, can greatly improve the stability of the sol dispersion. On the other hand, the effect of anhydrous ethanol as the cosolvent on the stability of the sol dispersion can be ignored, and a little difference appears only in two samples (T1K0.5E0/TPGDA and T1K0.5E3/TPGDA) with the mole ratio between MPS and TEOS equal to 0.5/1.
$3.3(\mathrm{C}=\mathrm{C})$ double bond conversion of UV-curable hybrid coating formulations

Compared to T1K3E0/TPGDA and T1K3E8/TPGDA, two stable sol dispersions T1K2E0/TPGDA and T1K2E6/ TPGDA containing more silicone were chose to mix with the UV-curable organic composition (SM6104 and TPGDA) forming UV-cured coating materials H-TIK2E0A and H-T1K2E6-A, respectively. Moreover, considering the potential impact of residual solvent on performances of the hybrid coating materials, two sols T1K2E0 and T1K2E6 were used to form samples H-TIK2E0 and H-T1K2E6 in the same operation, respectively.

According to relevant literatures [25, 38], their UVcuring properties were studied by FTIR spectroscopy, which is based on recording the change in $(C=C)$ double bond absorption of acrylate groups at $1,634 / \mathrm{cm}$. In one set of experiments, the formulations were coated on $\mathrm{KBr}$ disks in the usual way. The infrared spectrum of the non-irradiated material was recorded and then the film was subjected to UV beaming for $10 \mathrm{~s}$ to ensure the maximum conversion. From Fig. 7, it can be found that $(\mathrm{C}=\mathrm{C})$ double bond conversions of the blank, H-T1K2E6, H-T1K2E6-A, H-TIK2E0 and H-TIK2E0-A are 88, 75, 72, 66 and $65 \%$, respectively. It should be mentioned that the acrylate group of MPS may have a lower activity, and is restricted by the colloidal matrix [25, 38]. Based on the reason, it can be explained that, (1) $(\mathrm{C}=\mathrm{C})$ double bond conversions of the hybrid system (H-T1K2E6, H-T1K2E6-A, H-TIK2E0 and H-TIK2E0-A) are lower 13-23\% than that of the blank; (2) in the hybrid system, conversions of H-TIK2E0 and H-TIK2E0-A are lower than those of the other two because
Fig. 6 Deterioration times of different sol dispersions after the distillation

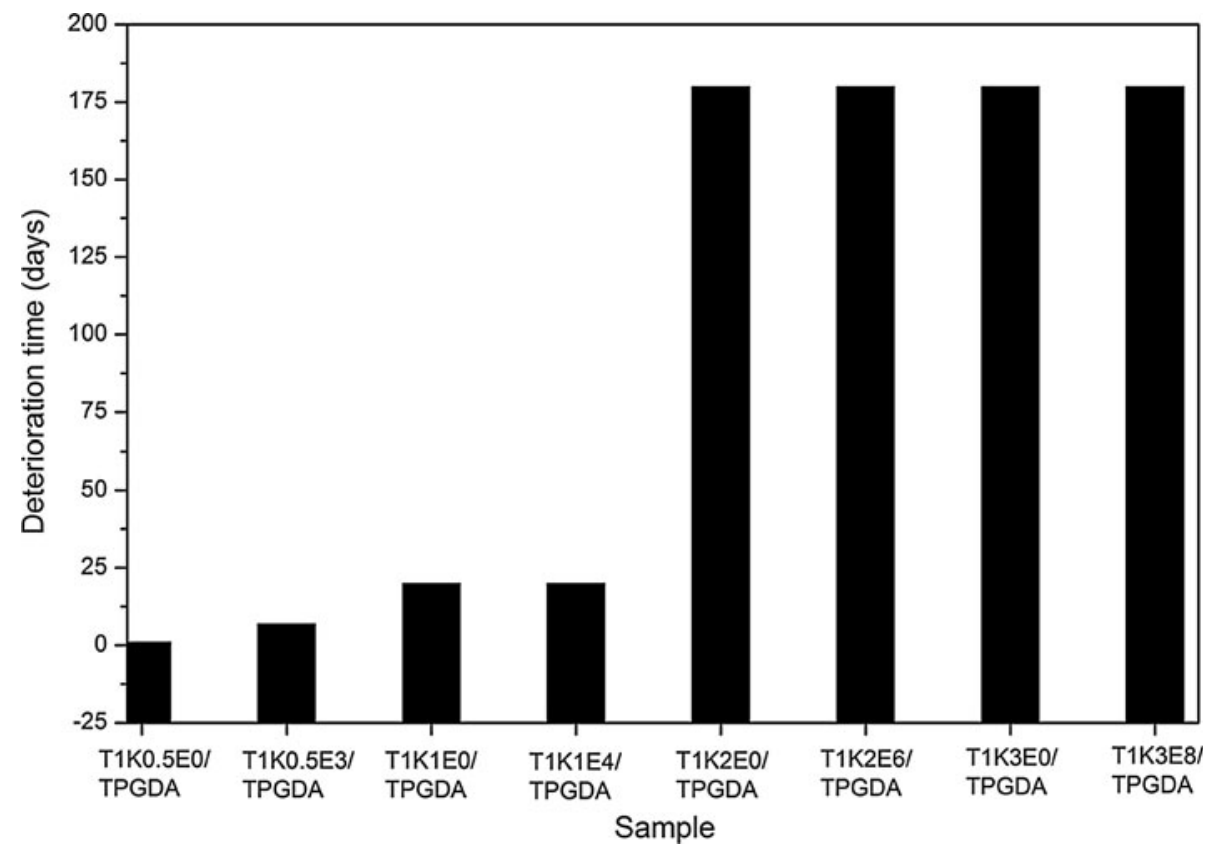




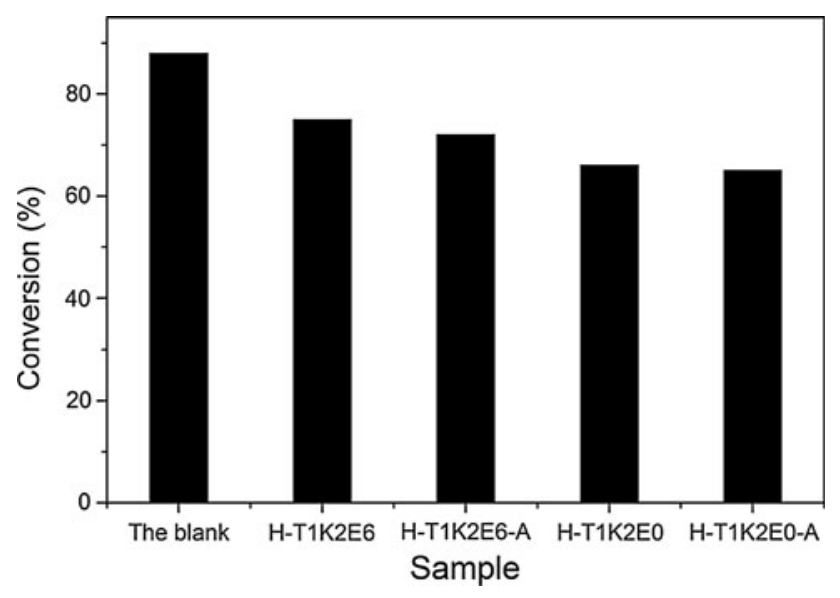

Fig. 7 The $(\mathrm{C}=\mathrm{C})$ double bond conversion of UV-curable coating formulations

of their wider diameter distributions and larger average sizes mean that more acrylate groups of MPS present in the internal matrix of the colloidal particles; (3) conversions of H-T1K2E6-A and H-TIK2E0-A are slightly lower 3 and $1 \%$ than those of H-T1K2E6 and H-TIK2E0, respectively. It is the mutually offsetting effort of two factors: the distillation treatment may lead to further aggregation of collide particles and TPGDA as dispersion medium can improve the reaction chance of acrylate groups of colloidal particles and TPGDA.

\subsection{Morphology of cured hybrid coating materials}

In order to observe whether the incorporated sol results in the obvious phase separation, morphologies of fractured surface of two hybrid coating materials (a) H-TIK2E6-A and (b) H-T1K2E0-A were observed by scanning electron microscope. Figure 8 showed their SEM images. It can be seen that the obvious phase separation occurs in H-TIK2E0-A because of bigger colloid particles of TIK2E0 (shown in Fig. 8b), while the phase separation has not been observed in H-T1K2E6-A. It is clear that the structure of H-T1K2E6-A is more perfect, and is expected to have better performances.

\subsection{Thermal gravimetric analysis}

Thermal stabilities of the blank, H-TIK2E0, H-T1K2E6, H-TIK2E0-A and H-T1K2E6-A were discussed. Their TGA curves are shown in Fig. 9. The temperature of $5 \mathrm{wt} \%$ weight loss $\left(\mathrm{T}_{5 \%}\right)$, the temperature of $50 \mathrm{wt} \%$ weight loss $\left(\mathrm{T}_{50 \%}\right)$, and char yield at $700{ }^{\circ} \mathrm{C}$ were obtained from the TG curves. These data are presented in Table 2.

As can be seen from Fig. 9, the hybrid system has two main stages of degradation, which two temperature ranges are mainly about 200 and $>370{ }^{\circ} \mathrm{C}$. Moreover, it can be found that, (1) $\mathrm{T}_{5 \%}$ of H-T1K2E6 is lower $19.08{ }^{\circ} \mathrm{C}$ than that of H-T1K2E0. This is because the additional cosolvent means that the solvents in the sol is more, and the fast UVcuring process also inhibits the volatilization of the solvents. Their char yields are not directly comparable because of the different content of the solvent in two sols; (2) $\mathrm{T}_{5 \%}$ of H-T1K2E6-A is lower $29.63{ }^{\circ} \mathrm{C}$ than that of $\mathrm{H}-\mathrm{T} 1 \mathrm{~K} 2 \mathrm{E} 0-\mathrm{A}$, but their $\mathrm{T}_{50 \%}$ and char yield are very close. Their $5 \%$ weight loss are including the residual solvents and the dehydration of $\mathrm{Si}-\mathrm{OH}$ groups, but the solvents in these two sol dispersions T1K2E6/TPGDA and T1K2E0/ TPGDA are the same, so their different content of $\mathrm{Si}-\mathrm{OH}$ groups should be the main reason to cause the $\mathrm{T}_{5 \%}$ difference between their aimed products H-T1K2E6-A and H-T1K2E0-A, respectively. It had been confirmed by Fig. 2 that the sol T1K2E6 with smaller colloid particles means that it has the larger surface area and higher surface free energy inducing the easier dehydration of $\mathrm{Si}-\mathrm{OH}$ groups, which also likely cause the lower $\mathrm{T}_{5 \%}$ of H-T1K2E6-A; (3) $\mathrm{T}_{5 \%}, \mathrm{~T}_{50 \%}$ and char yield of H-T1K2E0$\mathrm{A}$ and H-T1K2E6-A are significantly higher than those of H-T1K2E0 and H-T1K2E6. This showed that the distillation process is especially necessary for the thermal stability of

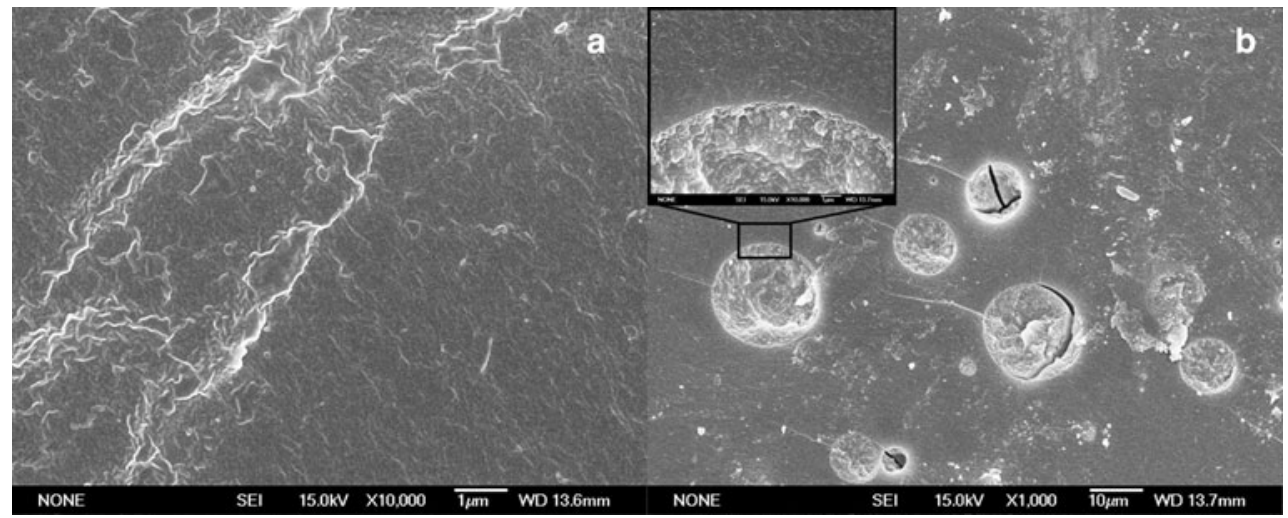

Fig. 8 SEM images of fractured surface of a H-TIK2E6-A and b H-T1K2E0-A 


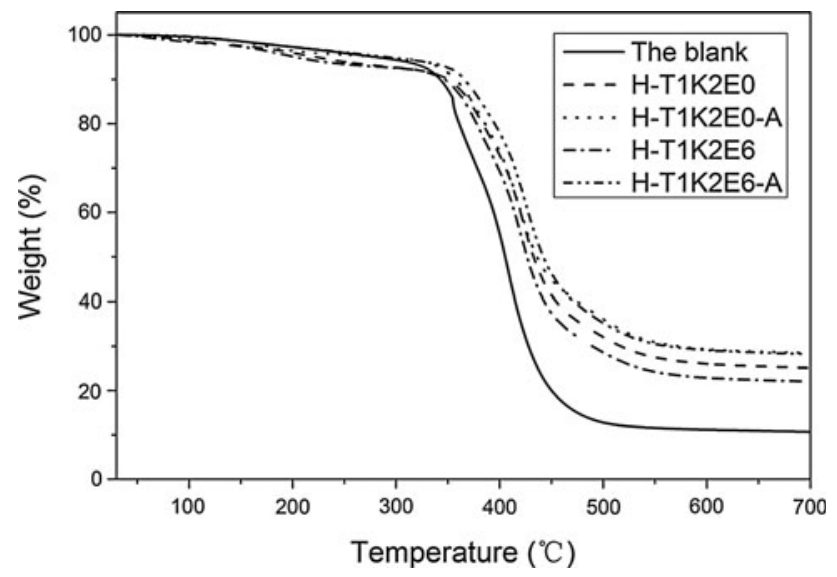

Fig. 9 TGA curves for the hybrid coating materials

Table 2 TGA data for the hybrid coating materials

\begin{tabular}{lllll}
\hline Sample & $\begin{array}{l}\text { Residual } \\
\text { solvent }(w t \%)\end{array}$ & $\begin{array}{l}\mathrm{T}_{5 \%} \\
\left({ }^{\circ} \mathrm{C}\right)\end{array}$ & $\begin{array}{l}\mathrm{T}_{50 \%} \\
\left({ }^{\circ} \mathrm{C}\right)\end{array}$ & $\begin{array}{l}\text { Char yield at } \\
700{ }^{\circ} \mathrm{C}(\mathrm{wt} \%)\end{array}$ \\
\hline H-T1K2E6 & 18.16 & 203.35 & 426.48 & 22.09 \\
H-T1K2E6-A & 18.5 & 261.34 & 427.31 & 29.01 \\
H-T1K2E0 & 61.15 & 222.43 & 432.77 & 25.13 \\
H-T1K2E0-A & 68.9 & 288.27 & 435.90 & 28.51 \\
The blank & - & 280.19 & 405.38 & 10.68 \\
\hline
\end{tabular}

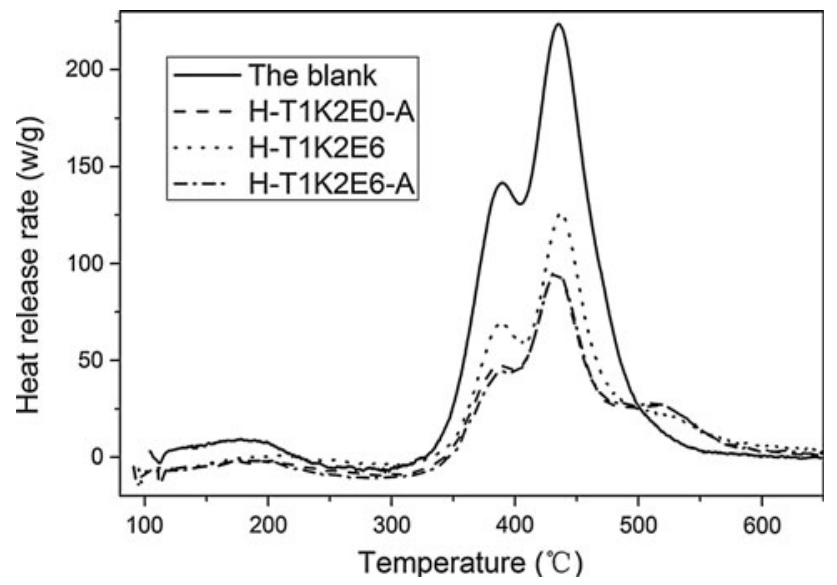

Fig. 10 HRR curves of UV-cured hybrid coating materials

these materials. Moreover, by the way, compared with the blank, $\mathrm{T}_{50 \%}$ and char yield of the hybrid system are higher. It means that incorporation of the sol can improve the thermal stability of pure organic system due to the excellent thermal stability of $\mathrm{Si}$ or its oxide.

\subsection{Combustion behaviors}

The effects of the cosolvent anhydrous ethanol and the distillation process on MCC results, LOI and flame
Table 3 Microscale combustion calorimeter data for the samples

\begin{tabular}{lccccc}
\hline Sample & $\begin{array}{l}\text { pHRR } \\
(\mathrm{w} / \mathrm{g})\end{array}$ & $\begin{array}{l}\text { THR } \\
(\mathrm{kJ} / \mathrm{g})\end{array}$ & $\begin{array}{l}\mathrm{T}_{\max } \\
\left({ }^{\circ} \mathrm{C}\right)\end{array}$ & $\begin{array}{l}\text { LOI } \\
(\%)\end{array}$ & FPV \\
\hline H-T1K2E6-A & 129.8 & 11.6 & 439.3 & 19.8 & 18.2 \\
H-T1K2E0-A & 129.9 & 11.7 & 431.7 & 19.6 & 18.9 \\
H-T1K2E6 & 169.4 & 15.1 & 435.5 & 18.2 & 43.2 \\
H-T1K2E0 & - & - & - & 18.4 & 33.1 \\
The blank & 223.7 & 19.7 & 435.3 & 20.0 & 18.7 \\
\hline
\end{tabular}

propagation velocity (FPV) of UV-cured hybrid coating materials were investigated. Figure 10 showed HRR curves of UV-cured hybrid coating materials, and Table 3 displayed the part data recorded in MCC experiments and their LOI and FPV.

From Table 3, it can be seen that the limiting oxygen index (LOI) of H-T1K2E0 and H-T1K2E6 are 18.4 and $18.2 \%$, lower than those (19.6 and $19.8 \%$ ) of H-T1K2E0A and H-T1K2E6-A, respectively, while their flame propagation velocity (FPV) are 33.1 and $43.2 \mathrm{~mm} / \mathrm{min}$, higher than those of the latter two. Two results show that the distillation process is still necessary to improve LOI and PFV of these hybrid coating materials. In addition, differences of LOI and FPV of H-T1K2E0-A and H-T1K2E6-A are very small. It means that the improvement brought by the morphology and particle size of the sols is negligible. LOI (19.6 and $19.8 \%$ ) of H-T1K2E0-A and H-T1K2E6-A are slightly lower than that of the blank. This could be caused by volatilization and combustion of a slight residual solvent introduced by the sol.

From Fig. 10 and several MCC data in Table 3, the similar improvement was also found. The peak heat release rate (pHRR) and the total heat release (THR) of H-T1K2E6 were $169.41 \mathrm{w} / \mathrm{g}$ and $15.1 \mathrm{~kJ} / \mathrm{g}$, much more than those (129.8 w/g, $11.6 \mathrm{~kJ} / \mathrm{g}$ ) of H-T1K2E6-A. Obviously, the distillation process reduces content of the combustible solvent, thereby reducing the heat release of the material. Moreover, the difference of MCC data between H-T1K2E6-A and H-T1K2E0-A is negligible. It implied that morphology of the sol is not the decisive factor for pHRR and THR of the hybrid system. Compared with the blank, pHRR and THR of H-T1K2E6-A and H-T1K2E0-A are decreased by roughly 42 and $41 \%$, respectively. The result showed that the hybrid system releases less heat during the combustion and less risk to ignite other combustibles.

The data of MCC, LOI and FPV display that H-T1K2E6-A and H-T1K2E0-A are better than H-T1K2E6 and H-T1K2E0 in the combustion performance, so they were also coated on the wood floor and carried on the flammability experiment. Time to ignition, the flame duration time of the coated substances after the withdrawal of the experimental fire, 

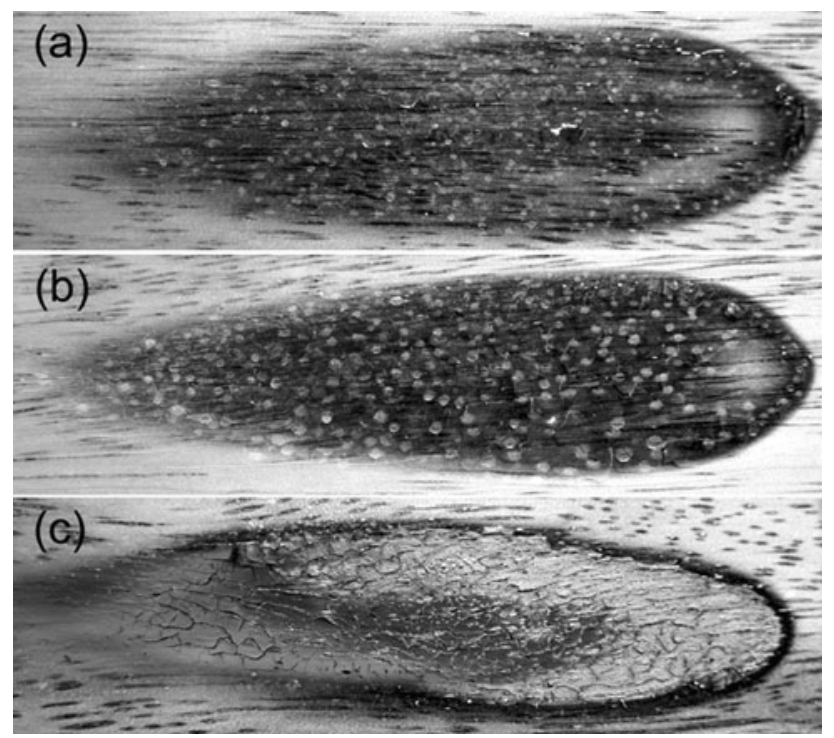

Fig. 11 Optical images of the substances coated by a H-T1K2E6-A, b H-T1K2E0-A and c the blank after flammability test

and morphology of the coating after combustion are recorded. Figures 11 and 12 show their optical images and SEM images after the flammability test, respectively. Table 4 displays some flammability testing data.

As can be seen from Fig. 11, most of the combustion area of the blank are gray, and the obvious residual carbon layer was not observed by visual inspection. In contrast, under the same combustion condition, and H-T1K2E6-A and H-T1K2E0-A remain basically intact, and the very small area contacted with the flame is burned through, and the substrate is protected well. Moreover, compared with $\mathrm{H}-\mathrm{T} 1 \mathrm{~K} 2 \mathrm{E} 6-\mathrm{A}$, the dotted cracking zone of H-T1K2E0-A is bigger and more widely dispersed. This may be because the bigger colloidal particles introduced by the sol T1K2E0 cause the greater thermal stress. SEM images shown in Fig. 12 clearly showed the differences in the morphology of the blank coating (a) and the hybrid coating H-T1K2E6A (b) after the combustion. The blank with fluffy and cracked structure cannot prevent obviously the air to
Table 4 The data of flammability test of the coatings

\begin{tabular}{llc}
\hline Sample & Time to ignition (s) & Flame duration time (s) \\
\hline H-T1K2E6-A & 32 & 0 \\
H-T1K2E0-A & 29 & 0 \\
The blank & 15 & 105 \\
\hline
\end{tabular}

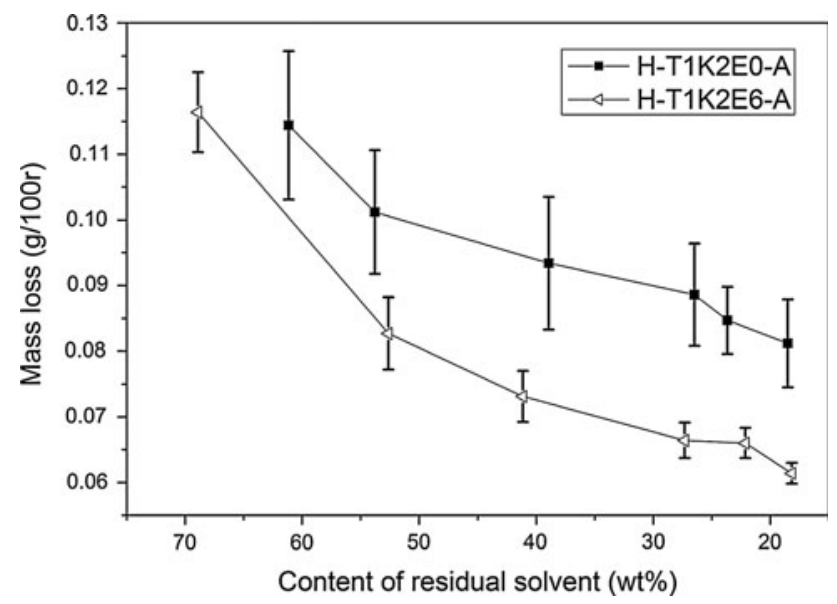

Fig. 13 The effect of the residual solvent on abrasion resistance of H-TIK2E6-A and H-T1K2E0-A

intrude the substrate or the flame to contact directly the substrate, while the hybrid coating H-T1K2E6-A with the intact surface attached by few residue after the combustion which allowed the substrate to survive in the fires.

The different morphology of the blank and H-T1K2E6A after the combustion indicated their different behaviors against the fire which were quantified by two indexes including time to ignition and flame duration time, shown in the Table 4. At first, time to ignition of H-T1K2E6-A (32 s) and H-T1K2E0-A (29 s) is about two times of that of the blank (15 s). Secondly, the flaming combustion of the substrate protected by H-T1K2E6-A and H-T1K2E0-A immediately stopped after the experimental fire was evacuated, while the flaming combustion of the substrate
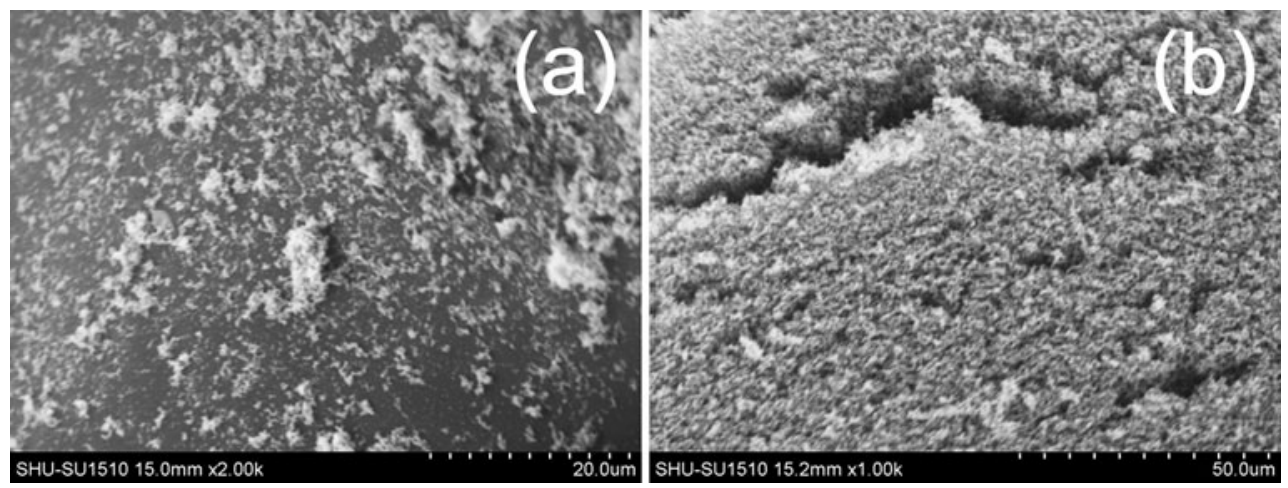

Fig. 12 SEM images of the coating a H-T1K2E6-A and b the blank after flammability test 
Table 5 The physical properties of the UV-cured coatings

\begin{tabular}{lllllll}
\hline Sample & $\begin{array}{l}\text { Residual solvent } \\
(\mathrm{wt} \%)\end{array}$ & $\begin{array}{l}\text { Pencil hardness } \\
(\mathrm{H})\end{array}$ & $\begin{array}{l}\text { Pendulum hardness } \\
(\mathrm{s})\end{array}$ & $\begin{array}{l}\text { Cross-cut } \\
\text { adhesion }\end{array}$ & $\begin{array}{l}\text { Scratch resistance } \\
(\mathrm{g})\end{array}$ & $\begin{array}{l}\text { Transmittance } \\
(\%)\end{array}$ \\
\hline The blank & - & 3 & 260 & $4 \mathrm{~B}$ & 300 & 92.1 \\
H-TIK2E6-A & 18.16 & 6 & 338 & $5 \mathrm{~B}$ & 800 & 91.6 \\
H-TIK2E0-A & 18.5 & 6 & 340 & $4 \mathrm{~B}$ & 800 & 91.1 \\
\hline
\end{tabular}

coated by the blank coating was lasting for $105 \mathrm{~s}$. The results indicate that this type of the UV-cured hybrid coating can protect the substrate from fire to a certain extent.

\subsection{The physical properties of hybrid coatings}

The effects of content of the residual solvent and the cosolvent anhydrous ethanol on several usual physical properties of the hybrid coatings including hardness, abrasion resistance and scratch resistance were also investigated. Each result reported in this paper was an average of five separate measurements performed.

Abrasion resistance represents the ability of coatings to resist grinding abrasion. Figure 13 presents the mass loss of the coatings after abrasion test with 100 cycles. From the figure, it can be also found that the mass loss of the UVcured hybrid coatings H-T1K2E0-A and H-TIK2E6-A decreased from 0.1144 and 0.1164 to 0.0812 and $0.0614 \mathrm{~g} /$ $100 \mathrm{r}$, when content of residual solvent of the sols T1K2E0 and TIK2E6 was decreased from 61.15 and 68.9 to 18.5 and $18.16 \mathrm{wt} \%$, respectively. This result also implied that when content of the residual solvent was close, the mass loss of H-T1K2E0-A was more than that of H-TIK2E6-A. Moreover, another phenomenon was also concerned that the deviation average of the mass loss of H-T1K2E0-A was also far greater than that of H-TIK2E6-A. The sol T1K2E0 with poor homogeneous colloidal particles should be still the main cause of this difference. The results indicated that two methods including to use the sol in which the colloidal particles are smaller and more homogeneous, and to reduce content of residual solvent in the sol, can improve abrasion resistance of the hybrid coatings. Similar results appeared in the scratch resistance, pendulum hardness and pencil hardness experiments. The physical properties of two optimized samples H-TIK2E6-A and H-T1K2E0-A were recorded in Table 5 and not be repeated here.

\section{Conclusions}

In this research, a series of silica sols were prepared based on sol-gel reactions using the different mole ratio of MPS and TEOS, and then the solvent in these sols was removed by the vacuum distillation method. The solvent in the sol after the distillation is less, deterioration time of the sol dispersions is shorter, but it can be lengthened by the increasing content of the sol precursors MPS and incorporating TPGDA into the sol. As a result, optimized sols can maintain stable for over 180 days.

When optimized sol dispersions were used to form the UVcuring organic-inorganic hybrid coatings, the research showed that $(\mathrm{C}=\mathrm{C})$ double bond conversions of the hybrid system are lower than that of the pure organic sample, and the improvement of controlling the residual solvent in the sol on performances of the hybrid coatings was more remarkable than adjusting the morphology and particle size of the sol. In addition, compared with pure UV-cured organic coating, the hybrid coating material applied to the surface of the wood floor substrate can delay time to ignition of the substrate because it rapidly turned into the nonflammable protective layer in the burning test, and also let the burning substrate immediately extinguished after the removal of the experimental fire. The results implied that this type of the sol dispersions with good stability has the considerable practical application value in improving the flame retardancy of the UV-cured coatings.

Acknowledgments This work was supported by International Cooperation Fund of Shanghai Science \& Technology Committee (Grant No. 10520706100), Major science and technology project of Science Technology Department of Zhejiang Province (2011C11005), Environment Condition Programme of Shanghai (10dz2252300) and Innovation Program of Shanghai Municipal Education (10YZ02). The authors would like to thank Jijiang Hu and Juping Ding for TG and MCC measurements.

Open Access This article is distributed under the terms of the Creative Commons Attribution License which permits any use, distribution, and reproduction in any medium, provided the original author(s) and the source are credited.

\section{References}

1. Kickelbick G (2007) Hybrid materials: synthesis, characterization, and applications. Wiley, London

2. Samuneva B, Kabaivanova L, Chernev G, Djambaski P, Kashchieva E, Emanuilova E, Salvado IMM, Fernandes MHV, Wu A 
(2008) Sol-gel synthesis and structure of silica hybrid materials. J Sol-Gel Sci Technol 48(1-2):73-79

3. Chiang CL, Ma CCM (2002) Synthesis, characterization and thermal properties of novel epoxy containing silicon and phosphorus nanocomposites by sol-gel method. Eur Polym J 38(11): 2219-2224

4. Chou TP, Chandrasekaran C, Limmer SJ, Seraji S, Wu Y, Forbess MJ, Nguyen C, Cao GZ (2001) Organic-inorganic hybrid coatings for corrosion protection. J Non-Cryst Solids 290(2-3):153-162

5. Liu J, Berg JC (2007) An aqueous sol-gel route to prepare organicinorganic hybrid materials. J Mater Chem 17(41):4430-4435

6. Fusheng L, Shuxue Z, Limin W (2005) Preparation and characterization of UV-curable MPS-modified silica nanocomposite coats. J Appl Polym Sci 98(5):2274-2281

7. Bauer F, Flyunt R, Czihal K, Ernst H, Naumov S, Buchmeiser MR (2007) UV curing of nanoparticle reinforced acrylates. Nuclear Instrum Methods B 265(1):87-91

8. Isin D, Kayaman-Apohan N, Gungor A (2009) Preparation and characterization of UV-curable epoxy/silica nanocomposite coatings. Prog Org Coat 65(4):477-483

9. Wouters MEL, Wolfs DP, van der Linde MC, Hovens JHP, Tinnemans AHA (2004) Transparent UV curable antistatic hybrid coatings on polycarbonate prepared by the sol-gel method. Prog Org Coat 51(4):312-320

10. Innocenzi P, Brusatin G (2004) A comparative FTIR study of thermal and photo-polymerization processes in hybrid sol-gel films. J Non-Cryst Solids 333(2):137-142

11. Landry V, Riedl B, Blanchet P (2008) Alumina and zirconia acrylate nanocomposites coatings for wood flooring: photocalorimetric characterization. Prog Org Coat 61(1):76-82

12. Lu N, Lu X, Jin X, Lu C (2007) Preparation and characterization of UV-curable $\mathrm{ZnO} /$ polymer nanocomposite films. Polym Int 56(1):138-143

13. Schwalm R (2006) UV coatings: basics, recent developments and new applications. Elsevier, Amsterdam

14. Cheng L, Zhang Y, Shi W (2012) Photoinitiating behavior of benzophenone derivatives covalently bonded tertiary amine group for UV-curing acrylate systems. Polym Adv Technol 23(3): 669-676

15. Gómez-Romero P, Romero PG, Sanchez C (2006) Functional hybrid materials. Wiley, London

16. Gawande MB, Deshpande SS, Sonavane SU, Jayaram RV (2005) A novel sol-gel synthesized catalyst for Friedel-Crafts benzoylation reaction under solvent-free conditions. J Mol Catal A Chem 241(1-2):151-155

17. Alexandru M, Cazacu M, Nistor A, Musteata VE, Stoica I, Grigoras C, Simionescu BC (2010) Polydimethylsiloxane/silica/ titania composites prepared by solvent-free sol-gel technique. J Sol-Gel Sci Technol 56(3):310-319

18. Benmokhtar S, El Jazoulia A, Chaminade JP, Gravereau P, Menetrier M, Bouree F (2007) New process of preparation, structure, and physicochemical investigations of the new titanyl phosphate $\mathrm{Ti}_{2} \mathrm{O}\left(\mathrm{H}_{2} \mathrm{O}\right)\left(\mathrm{PO}_{4}\right)(2)$. J Solid State Chem 180(10): 2713-2722

19. Zou KR, Soucek MD (2004) UV-curable organic-inorganic hybrid film coatings based on epoxidized cyclohexene derivatized linseed oil. Macromol Chem Phys 205(15):2032-2039

20. Li FS, Zhou SX, Gu GX, You B, Wu LM (2005) Preparation and characterization of ultraviolet-curable nanocomposite coatings initiated by benzophenone/n-methyl diethanolamine. J Appl Polym Sci 96(3):912-918
21. Li FS, Zhou SX, Wu LM (2005) Effects of preparation method on microstructure and properties of UV-curable nanocomposite coatings containing silica. J Appl Polym Sci 98(3):1119-1124

22. Zhang HB, Wang JY, Li LK, Song Y, Zhao MS, Jian XG (2008) Synthesis of liquid polysilisiquioxane resins and properties of cured films. Thin Solid Films 517(2):857-862

23. Kahraman MV, Bayramoglu G, Boztoprak Y, Gungor A, Kayaman-Apohan N (2009) Synthesis of fluorinated/methacrylated epoxy based oligomers and investigation of its performance in the UV curable hybrid coatings. Prog Org Coat 66(1):52-58

24. Han YH, Taylor A, Mantle MD, Knowles KM (2007) Sol-gelderived organic-inorganic hybrid materials. J Non-Cryst Solids 353(3):313-320

25. Apohan NK, Karatas S, Bilen B, Guengoer A (2008) In situ formed silica nanofiber reinforced UV-curable phenylphosphine oxide containing coatings. J Sol-Gel Sci Technol 46(1):87-97

26. Tan H, Yang D, Xiao M, Han J, Nie J (2009) Preparation of silica/polyurethane nanocomposites by UV-induced polymerization from surfaces of silica. J Appl Polym Sci 111(4):1936-1941

27. Hsiang HI, Chang YL, Chen CY, Yen FS (2011) Silane effects on the surface morphology and abrasion resistance of transparent $\mathrm{SiO}_{2} / \mathrm{UV}$-curable resin nano-composites. Appl Surf Sci 257(8): 3451-3454

28. Schwalm R (2007) UV coatings: basics, recent developments and new applications. Elsevier, Amsterdam

29. Fidalgo A, Ilharco LM (2001) The defect structure of solgel-derived silica/polytetrahydrofuran hybrid films by FTIR. J Non-Cryst Solids 283(1-3):144-154

30. Medda SK, Kundu D, De G (2003) Inorganic-organic hybrid coatings on polycarbonate: spectroscopic studies on the simultaneous polymerizations of methacrylate and silica networks. J Non-Cryst Solids 318(1-2):149-156

31. Galeener FL (1979) Band limits and the vibrational spectra of tetrahedral glasses. Phys Rev B 19(8):4292-4297

32. Stangar UL, Sassi A, Venzo A, Zattin A, Japelj B, Orel B, Gross S (2009) IR and NMR time-resolved studies on the hydrolysis and condensation of methacryloxyalkylsilanes. J Sol-Gel Sci Technol 49(3):329-335

33. Matos M, Ilharco L, Almeida R (1992) The evolution of TEOS to silica gel and glass by vibrational spectroscopy. J Non-Cryst Solids 147:232-237

34. Huang SL, Chin WK, Yang WP (2004) Viscosity, particle size distribution, and structural investigation of tetramethyloxysilane/ 2-hydroxyethyI methacrylate sols during the sol-gel process with acid and base catalysts. J Polym Sci Polym Phys 42(18):3476-3486

35. Sakka S (2005) Handbook of Sol-Gel science and technologyprocessing, characterization and applications. Kluwer, Dordrecht

36. Nassor ECD, Avila LR, Pereira PFD, Ciuffi KJ, Calefi PS, Nassar EJ (2011) Influence of the hydrolysis and condensation time on the preparation of hybrid materials. Mater Res Ibero Am J 14(1): $1-6$

37. Ogawa S, Decker EA, McClements DJ (2003) Production and characterization of $\mathrm{O} / \mathrm{W}$ emulsions containing cationic droplets stabilized by lecithin-chitosan membranes. J Agric Food Chem 51(9):2806-2812

38. Altintas Z, Karatas S, Kayaman-Apohan N, Gungor A (2011) The maleimide modified epoxy resins for the preparation of UVcurable hybrid coatings. Polym Adv Technol 22(2):270-278 